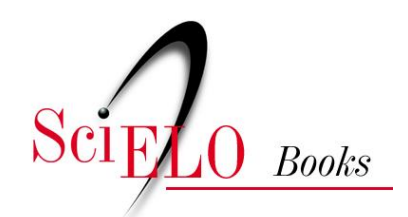

\title{
Os milagres da Tenda \\ uma leitura da mestiçagem em Jorge Amado
}

Humberto Luiz Lima de Oliveira

\section{SciELO Books / SciELO Livros / SciELO Libros}

OLIVEIRA, HLL. Os milagres da Tenda: uma leitura da mestiçagem em Jorge Amado. In:

SWARNAKAR, S., FIGUEIREDO, ELL., and GERMANO, PG., orgs. Nova leitura crítica de Jorge Amado [online]. Campina Grande: EDUEPB, 2014, pp. 34-59. ISBN 978-85-7879-328-9. Available from SciELO Books $<\underline{\text { http://books.scielo.org }>\text {. }}$

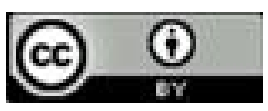

All the contents of this work, except where otherwise noted, is licensed under a Creative Commons Attribution $\underline{4.0 \text { International license. }}$

Todo o conteúdo deste trabalho, exceto quando houver ressalva, é publicado sob a licença Creative Commons Atribição 4.0.

Todo el contenido de esta obra, excepto donde se indique lo contrario, está bajo licencia de la licencia $\underline{\text { Creative }}$ Commons Reconocimento 4.0. 


\title{
Os milagres da Tenda: uma leitura da mestiçagem em Jorge Amado
}

\author{
Humberto Luiz Lima de Oliveira
}

\section{Introdução}

Quando vemos a reação negativa de setores da população brasileira com as políticas de ação afirmativa, notadamente no que tange às cotas para ingresso na universidade de candidatos de origens afrodescendente ou indígena, como também daqueles oriundos da escola pública cujo contingente populacional é inteiramente constituído de pobres e dentre eles os negros e mestiços majoritariamenteé que podemos compreender o pioneirismo de Jorge Amado ao inserir como herói positivo em suas narrativas literárias o negro Antonio Balduíno, em seu romance Jubiabá (1935). De fato, ao longo da sua carreira de escritor de sucesso, Amado povoaria seus textos literários com personagens negras e mestiças. E, de modo emblemático, em Tenda dos milagres (1969), romance que sintetizaria sua teoria da formação da cultura brasileira que o escritor baiano vê como inteiramente mestiça.

Claro que não desconheço as resistências de setores acadêmicos ao conceito de mestiçagem. De fato, poderse-ia elencar uma série de pesquisadores que preferem utilizar outras designações para se referir aos resultados dos entrecruzamentos. Dentre outras designações, só a título 
de ilustração, podemos encontrar criolização $0^{1}$, diversalite ${ }^{2}$, bibridismo ${ }^{3}$ tanto no Brasil quanto na América Latina, e que vão dando um certo conforto ao fugir do que pareceria um termo problemático ${ }^{4}$. No entanto, quando procuramos saber qual é mesmo o motivo da recusa em aceitar o termo mesticagem encontramos sempre a mesma resposta: "[...] o conceito de mestiçagem foi uma cilada da modernidade, pois sob a aparência da aceitação do múltiplo, se encobriu, na verdade, um projeto racista que previa a mistura das raças, mas com a predominância da raça branca e o branqueamento progressivo da

1 GLISSANT, Edouard, Le Discours antillais, Paris, Seuil, 1981, 504p.

2 BERNABE, Jean, «De l'oralité à la littérature antillaise » in (dir.) TETU LABSADE, Françoise, Littérature et dialogue interculturel, Sainte-Foy, Presses de l' université Laval, 1997.

3 BERND, Zilá, Literatura e identidade nacional, 2.ed. Porto Alegre: UFRGS, 2003,247p.

4 No entanto, assim como ressignificamos tantos outros conceitos e noções que foram durante longo tempo comprometidos, a exemplo de Negro, Mulher, Homossexual, Prostituta, enquanto intelectuais brasileiros, com origem na chamada "impureza", talvez seja tempo de recusarmos qualquer noção hegemônica de identidade. Neste sentido, seria bom que pudéssemos aceitar que o conceito de mestiçagem pode ser lido fora das armadilhas da teoria do branqueamento defendida pelas elites intelectuais e políticas do século passado, ou pelos que preconizam uma certa exagerada "fluidez" ou "liquidez" das questões indenitárias, cf BAUMAN, Zygmunt. Vida líquida. Tradução Carlos Alberto Medeiros. Rio de Janeiro: Zahar, 2007. 
população $[. . .]^{5 "}$ É interessante observar que, embora aceite operar a partir do conceito de híbrido ${ }^{6}$ ofertado por Canclini, esta autora percebe quew também esse termo pode encerrar armadilhas perigosas, constituindo-se em mais uma "[...] utopia da pós-modernidade, a qual estaria encobrindo um certo imperialismo cultural, pronto a apropriar-se de elementos de culturas marginalizadas para reutilizá-los a partir de paradigmas de aceitabilidade das culturas hegemônicas $[. . .]^{7 ’}$.

De fato, o conceito de mestiçagem esteve carregado de negatividade. Não importa qual seja o seu nome, o mestiço vem ao mundo sob o signo da dúvida. Suspeita-se de ser doentio, de não ser capaz de autodeterminar-se e mesmo de não ser capaz de viver em sociedade. Nele estariam estampados os signos da 'impureza' e da "degeneração" da raça. Dele seriam as representações mais doentias que a literatura e o cinema, posteriormente, iriam oferecer.

5 BERND, op. cit. p. 18.

6 É bom não se esquecer que o conceito de híbrido remete diretamente à noção de hybris que, por sua vez, remete a "peso excessivo, força exagerada". A partir do adjetivo híbrido, do latim bybrida, os gregos teriam utilizado esse termo para condenar a misicigenação, vista como "violação das leis naturais". Observe-se também que havia uma forte crença de que o híbrido, o miscigenado seria tomado por forças incontroláveis (a fúria ou o orgulho, por exemplo). Neste caso, o indivíduo estaria sujeito à incapacidade de autogerir-se e autocontrolar-se, sendo instado por sentimentos violentos que as paixãos exageradas(doenças) iriam impulsionar sobre seu ser que estaria em permanente estado de desequilíbrio e irracionalidade.

7 BERND, ibid. 
Importa saber que, ao indivíduo que seria portador de marcas de uma dupla identidade, o modelo binário de pensamento ( $=$ ou isto, ou aquilo) consideraria demasiado fora dos padrões, excêntrico, logo, inaceitável, um 'terceiro excluído', não sendo nem A, nem B. Assim, o mestiço seria apreendido como, "o que não encontra lugar entre os demais", pois que seria "um sem par", "um sem igual”, isto é, não seria idêntico a nenhum dos grupos que o circundam e o comprimem e aos quais poderia alegar uma relação de pertença ${ }^{8}$.

No entanto, gostaria de colocar essa questão em outros

8 Em caráter exemplar, o cinema estadunidense foi pródigo em representar o mestiço de branco e índigena que não conseguia definir o seu espaço,sob o nome de Renegado. Na verdade, este indivíduo não conseguiria jamais definir seu grupo de pertença, e pior ainda, em caso de desejar optar pelo grupo dominante ou no caso branco-europeu, seria rejeitado, pois carregaria consigo as marcas muito evidentes de sua própria estranheza. Basta lembrar, por exemplo, o filme de John Ford, Rastros de ódio ( The Searches), de 1956; ou ainda Pequeno Grande Homem (Little Big Man) EUA - 1970 (dir.) Arthur Penn, com Dustin Hoffman no papel do mestiço Jack Crabb. Na literatura brasileira, O Mulato (1881) um clássico do Naturalismo, de autoria de Aluísio de Azevedo traz o drama de Raimundo que, desconhecendo sua cor, "branqueado" pela ascensão social, ao mudar de domicílio, defronta-se com preconceitos que não consegue entender. No que tange à figura da mulata, tanto a literatura quanto a música popular brasileira seriam pródigas em defini-la com as marcas do exagero, logo da desmedida, e por isso com forte apelo sexual. Cf. QUEIROZ FILHO, Teófilo de. Preconceito de Cor e a Mulata na Literatura Brasileira. São Paulo: Ática,1975. 
termos, ou seja, se não seria possível pensar o mestiço como sendo aquele que pode transitar - sem esconder por vezes seu desconforto, fruto das tensões das negociações nem sempre amigáveis, mas sempre possíveis - logo o que passeia, se move por e entre culturas diferentes, das quais, como verdadeiro canibal devora o que necessita para saciar sua fome de ser e de viver, de saber e fazer, de se fazer presente no mundo? É assim que compreendo e trago à discussão o conceito de mestiçagem. Sem nenhum medo de Ser, sem nenhum receio de parecer "exagerado". Ou de viver a incompletude do ser que é bem humana, como nos mostram a Filosofia do Ocidente e a sabedoria dos povos ditos arcaicos ou primitivos.

Assim pensando, proponho-me, neste trabalho, a fazer uma releitura do romance Tenda dos milagres, de Jorge Amado, para tentar responder a esta hipótese que me faz acreditar que o mestiço é aquele que pode estabelecer diálogo, logo conviver, de maneira plural, pois que carregaria em si mesmo toda uma memória genética que o leva a identificar-se com duas ou mais culturas, etnias, ou mesmo raças, se quisermos insistir nesta noção que é geradora de toda uma série de estereótipos ainda recorrentes no imaginário social da sociedade brasileira e até mesmo ocidental, sobretudo daquelas que conheceram a escravidão.

\section{Os milagres da tenda amadiana}

Somente quando nos lembramos do horror das teorias raciais é que podemos reconhecer a grandeza, a relevância e a pertinência para nós brasileiros e baianos, negros e 
mestiços, da obra amadiana e em especial de Tenda dos milagres e da personagem mais instigante, mais humana e mais comovente da literatura baiana. Pois Pedro Archanjo é desenhando, moldado e construído para se contrapor às teorias raciais, em especial, ao seu maior ideólogo por seu caráter de disseminador: Arthur de Gobineau que foi Embaixador francês na Corte imperial brasileira e que se admirava de como eram feios os brasileiros!?

Transplantada das ciências naturais, a noção de raça seria utilizada para explicar o desenvolvimento das civilizações, da evolução humana através dos tempos, e, a partir de apropriações dos conceitos de mestiçagem e degeneração das espécies, intelectuais europeus passariam a temer que o entrecruzamento de raças e culturas, por seu caráter de 'impureza' gerasse indivíduos doentios ou fracos, cuja debilidade de caráter fosse incompatível com a noção de darwinismo social então em voga. De fato, sobre o Negro, Gobineau, o principal difusor das teorias raciais diria que,

9 Morando no Rio de Janeiro, Embaixador francês na Corte imperial de Pedro II, Gobineau diria que os brasileiros eram incontestavelmente um povo feio, logo um resultado ruim da mestiçagem das raças. Aliás, para Gobineau e demais teóricos da pureza racial, toda e qualquer mistura ou mestiçagem teria como resultado a degeneração. Logo, o mestiço, o brasileiro típico era um degenerado, doentio, incapaz de progresso. Talvez por isso, durante muito tempo, décadas, talvez séculos, tenha-se pensado na impossibilidade de o Brasil vir a ser um grande país: pelo caráter mestiço do seu povo. 
[...] La variété mélanienne [à pigment de peau foncé] est la plus humble et gît au bas de échelle. Le caractère d' animalité empreint dans la forme de son bassin lui impose sa destinée, dès l'instant de sa conception. Elle ne sortira jamais du cercle intellectuel le plus restreint [...] Si ces facultés pensantes sont médiocres ou même nulles,[le Noir] possède dans le désir, et par suíte dans la volonté, une vigueur souvent terrible. Plusieurs de ses sens sont développés avec une vigueur inconnue aux deux autres races: le goût et l'odorat, principalement ${ }^{10}$.

Quanto à mestiçagem, objeto de nosso trabalho, Gobineau diria que, se num primeiro momento seus resultados não são nocivos, pois afinal, um elemento considerado "superior" é acrescido a outros considerados "inferiores", e assim fortaleceria o que 'naturalmente' seria 'fraco', no entanto, isto contribuiria, a médio e longo prazo para que o elemento dito 'superior', no caso a raça e a cultura branco-europeias, fossem pouco a pouco perdendo suas 'melhores

10 GOBINEAU, Arthur de, GOBINEAU, Joseph-Arthur, L'inégalité des races humaines, in http://www. http://www.philo5.com/Les\%20philosophes\%20Textes/Gobineau_InegaliteDesRacesHumaines.htm 
características':

[...] Le monde des arts et de la noble littérature résultant des mélanges du sang, les races inférieures améliorées, ennoblies, sont autant de merveilles auxquelles il faut applaudir. Les petits ont été élevés. Malheureusement les grands du même coup, ont été abaissés, et c' est un mal que rien ne compense ni ne répare.[...] La race blanche possédait originairement le monopole de la beauté, de l'intelligence et de la force.

(Ibid, os grifos são meus)

O certo é que, catalogadas de acordo com padrões eurocêntricos e numa escala que considerava a civilização branco-europeia como superior e, em graus tanto mais inferiores quanto mais se distanciassem do modelo dominante, as demais raças eram hierarquizadas, tendo no topo a raça branca e na base, num estágio de total despossessão das coisas do espírito, os povos sem escrita e sem Estado, apreendidos como alteridade radical, exotismo, diferença a ser eliminada por sua absoluta estranheza. Sociedade marcada pela herança escravagista e pelo passado colonial, o Brasil despontava no século XX como uma nação condenada ao atraso econômico por sua população, avaliada como "débil ou doentia" por seu 
caráter miscigenado (BASBAUM, 1976, p.65-78). Ficava assim legitimadas tanto a escravidão dos povos africanos quanto a própria colonização européia sobre vastas regiões do planeta. As teorias raciais constituíam-se numa contundente:

[...] investida contra os pressupostos igualitários das revoluções burguesas, cujo novo suporte intelectual concentrava-se na ideia de raça que, em tal contexto, aproximava-se cada vez mais da noção de povo. O discurso racial surgia, dessa maneira, como variante do debate sobre a cidadania, já que no interior desses novos modelos discorria-se mais sobre as determinações do grupo biológico do que sobre o arbítrio do indivíduo entendido como "um resultado, uma retificação dos atributos específicos da raça."

(SCHWARCZ, 1995, p.46-47)

É sob a sombra da suspeita de ser uma sociedade doentia que o Brasil desponta no século XX, com feridas ainda muito recentes de um passado escravocrata, com abismos sociais entre as classes e raças, onde predominavam tanto uma tentativa simiesca de copiar o estilo de vida da Europa, notadamente da França, quanto uma recusa da 
maioria da sua elite intelectual em aceitar a rica contribuição da herança cultural africana. Preconceito e racismo grassam na vida social de um país com vergonha de ser mestiço e desejoso de esconder as marcas étnicas que o faziam 'impuro', isto é, mestiço.

Protagonista de Tenda dos Milagres (1969), 'romance de tese', escrito por Jorge Amado, Pedro Archanjo pode ser visto como um lídimo representante de um povo que, não tendo trabalho organizado, vivendo na penúria e na pobreza, consegue manter sua liberdade individual intacta na medida em que permanece livre dos grilhões que a moral burguesa estabelece como normas de conduta. De fato, fora do sistema de produção capitalista, desassistido pelo Estado, um povo inteiro, milhares de homens, mulheres e crianças, descendentes diretos dos antigos escravos africanos, vivem, no Pelourinho e adjacências, o que o narrador chama de "mistério primitivo", tendo como contraponto a imponente Faculdade de Medicina da Bahia, "templo da ciência', onde predominam as teorias raciais, considerando o negro e o indígena como raças inferiores, e o mestiço dos entrecruzamentos sendo visto como degenerescência, ou doença. Na verdade, são esses homens e mulheres que, por não terem preço algum a pagar, pois nada recebem do Estado - o qual, aliás, não lhes assiste, pois não lhes reconhece a cidadania - por isso mesmo podem vivenciar o que Albert Camus considerava uma "barbárie outorgada e 
fecunda ${ }^{11}$ " e que confirma a existência de uma outra forma de viver, pensar, sonhar e sentir que o avanço do capitalismo - com a racionalização do trabalho e a domesticação dos instintos - poderia neutralizar, esmaecer ou anular.

Pedro Archanjo constitui-se no mestiço a quem a narrativa investe de positividade, ao torná-lo detentor das qualidades da racionalidade que os intelectuais da tradição evolucionista negavam, e que tornava pessimista a perspectiva de desenvolvimento real do capitalismo na nação brasileira por ser mestiça. Com a construção desta personagem, Jorge Amado mostra a chamada reversão dessa expectativa. Ou seja, este herói mulato deverá reconstituir no texto narrativo (= retrato da nação) a formação da identidade nacional, inserindo a contribuição da herança africana, em oposição à visão das classes dominantes representadas no romance pela figura de Nilo Argolo, o qual, em 1901, num congresso no Rio de Janeiro, publica $A$ degenerescência psíquica e mental dos povos mesticos - o exemplo da Babia, defendendo a tese de que o atraso socioeconômico da sociedade brasileira estaria diretamente vinculado à presença do elemento africano e sua "mistura" com o sangue branco-europeu, gerando uma "raça inferior".

11 Camus apresenta Babia de tous les saints (Jubiabá), na França de modo altamente elogioso e contrapondo a literatura produzida por Amado à cerebral, segundo ele, e fria literatura francesa da época. Cf. , Babia de Tous les Saints article d'Albert Camus (Alger Républicain, 9 avril 1939) http:// authologies.free.fr/amado.htm. 
Na verdade, o autodidata Pedro Archanjo é uma releitura que Amado faz da antropofagia. Falando corretamente línguas estrangeiras, com especial notoriedade para o seu "francês de Paris", além do espanhol, do inglês e do italiano, na biblioteca de Pedro Archanjo há um considerável acervo da cultura ocidental: de Franz Boas e a nova interpretação sobre as culturas, a Alexandre Dumas e Gobineau, dos mitos gregos ao cordel. É esta sua bagagem cultural tão vasta, aliada ao agudo senso de realidade que o faz ser capaz de articular relações, que o leva a escrever seus quatro livros ( $A$ vida popular na Babia - (1907); Influências africanas nos costumes da Babia -(1918); Apontamentos sobre a mesticagem nas Famílias baianas (1920) e A Culinária baiana: origens e preceitos (1930), os quais, cem anos depois, vão despertar o interesse de um catedrático estrangeiro e que vem à Bahia, exclusivamente, para constatar as afirmações de Pedro Archanjo sobre a miscigenação das raças e das culturas, como fator positivo, para comprovar que “[...] É mestiça a face do povo brasileiro e é mestiça a sua cultura"(TM, p.98).

Por isso, de modo metódico, sistemático, a personagem de Pedro Archanjo será capaz de competir no meio intelectual, mesmo se (ou principalmente se) contando com a ajuda divina, de Xangô, e da figura da branca-pobre Zabela, a “condessa de Água Brusca”, socialmente rejeitada por recusar os padrões da moral burguesa.

Dois mundos, duas cosmogonias: o mistério primitivo e a ruptura da ordem estabelecida pela racionalidade oci- 
dental vão confluir para possibilitar que Archanjo se aproprie das ferramentas necessárias para a transposição dos umbrais. E, para realizar a missão que lhe fora confiada pelos deuses afro-brasileiros, Archanjo deverá enquadrar-se na necessária disciplina, devendo abandonar a vida boêmia e malandra em que até então vivera.

Portanto, se a narrativa aponta para o papel de mediador reservado a Pedro Archanjo, outro espaço ser-lhe-á conferido. E, para que possa desempenhar a mediação necessária entre os mundos, ele contará com forças sobre-humanas, que o farão ultrapassar as limitações do plano social e econômico. E quem vai orientá-lo, direcioná-lo para a tarefa que lhe esperava é Majé Bassan, a analfabeta, a que vive na oralidade, no 'mistério primitivo".

É que, numa clara ironia, Jorge Amado brinca com os preconceitos e faz com que a voz que chamará Archanjo à ordem, que o disciplinará, que o incitará a cumprir sua obrigação, seja a voz da guardiã, da detentora do patrimônio religioso, cultural e linguístico da tradição africana, a grande sacerdotisa Majé Bassan.

De fato, é esta Mãe-de-Santo quem insistirá para que Archanjo passe da oralidade à escritura, preparando-se para enfrentar o perigo das idéias racistas, e abra caminho para um futuro que não seria tão remoto assim, e que deveria ser vivido por sua comunidade (p.97). Eis o que ela diz:

Soube que tu disse que vai escrever um livro, mas sei que tu não está fa- 
zendo, o teu fazer é da boca pra fora, tu se contenta com pensar. Tu passa a vida xeretando de um lado para outro, conversa aqui, conversa ali toma nota de um tudo e prá quê? Tu vai ser toda a vida contínuo de doutor? Só isso e mais nada? O emprego é pra teu de comer, para não passar necessidade. Mas não é para te bastar nem para te calar. Não é para isso que tu é Ojuobá.

(TM: 97)

Para tornar possível sua missão, os deuses concedem dons especiais a Pedro Archanjo:

Uma versão circula entre o povo dos terreiros, corre nas ruas da cidade: teria sido o próprio orixá (Xangô) quem ordena a Pedro Archanjo tudo ver, tudo saber, tudo escrever. Para isso fizera-o Ojuobá, os olhos de Xangô. [.....] Moço de vinte e poucos anos[....]Pedro Archanjo deu na mania de anotar histórias, acontecidos, casos, nomes, datas, detalhes insignificantes, tudo quanto se referisse à vida popular. Para quê? Quem sabe lá. Pedro Archanjo era cheio de qui- 
zilas, de saberes e certamente não se devera ao acaso sua escolha, tão moderno ainda, para alto posto na casa de Xangô: levantado e consagrado Ojuobá, preferido entre tantos e tantos candidatos, velhos de respeito e sapiência. Coube-lhe, no entanto, o título, com os direitos e deveres; não completara ainda trinta anos quando o santo o escolheu e o declarou: não pudera haver maior acerto- Xangô sabe os porquês.

(sic) (TM: 70)

Maior entre os anjos, por isso, Archanjo, Pedro será assim visto por dois mundos diferentes com seus respectivos imaginários: de um lado, será apenas um 'pobre, pardo e paisano'; de outro, um iluminado, um herói com halos de luz divina que tem por missão derrubar preconceitos e dar visibilidade social à cultura do povo negro-mestiço, resgatando orgulho e dignidade. Portanto, a incumbência de Pedro Archanjo é inserir na moldura do retrato da nação outras figuras que, na visão amadiana, compondo a brasilidade, ficaram excluídas do retrato indenitário nacional que as elites tentavam forjar.

Observe-se que, praticamente, ignorado em sua própria terra, depois de "descoberto" pelo "sábio americano", 
Pedro Archanjo passará a ter seu nome veiculado pela mídia, recebendo elogios de quem até mesmo o menosprezava. Jorge Amado aproveita para brincar com o pensamento subalterno que caracteriza grande parte da intelectualidade dos chamados países do 'terceiro mundo' ou colonizados, onde os intelectuais, assim como os professores universitários, tornam-se orgulhosos comentadores, repetidores.

Exemplo dos mais significativos do trânsito de Pedro Archanjo entre os mundos é o episódio do Terreiro d’Ilé Ogunjá. De fato, agonizante, antes de morrer, Majé Bassan, a grande sacerdotisa "[...] Mistura as línguas, usa palavras e frases iorubás, [...]” para transmitir a Pedro Archanjo "[...] a última lição, o ensinamento derradeiro [...]” (p.167) que o consagrará como babalorixá. Desta forma, doravante será ele o grande sacerdote responsável pela tradição, o indivíduo capaz de conjurar os deuses, de fazer acontecer o axé, logo de fazer o enunciado concretizar-se, plasmar-se no plano do real.

Assim, quando o comissário Pedrito Gordo chega com a milícia para impedir as celebrações e destruir o terreiro, Pedro Archanjo perceberá que um resto de respeito e temor ainda brilhava no olhar do bandido mais perigoso, Zé Alma Grande, ao entrar no espaço sagrado do terreiro, em plena noite de festa dos Orixás.

Adiantou-se o negro maior do que um sobrado.Ojuobá percebeu com os olhos de Xangô um átimo de vacilação no passo do facínora ao pe- 
netrar no recinto sagrado do Terreiro. Samuel Cobra Coral e Zacarias da Goméia tomaram posição, prontos para impedir qualquer protesto. Procópio prosseguiu na dança, era Oxossi,o caçador, senhor da selva, rei de Ketu.

Contam que, nessa hora exata, Exu, de volta do horizonte penetrou na sala. Ojuobá disse :Larioê, Exu !Foi tudo muito rápido. Quando Zé Alma Grande deu mais um passo em direção a Oxossi, encontrou pela frente a Pedro Archanjo. Pedro Archanjo, Ojuobá ou o próprio Exu conforme opinião de muitos. A voz se abriu imperativa no anátema terrível, na objurgatória falta!

-Ogun kapê Dan meji, Dan pe lú oniban!

Do tamanho de um sobrado, os olhos de assassino, o braço de guindaste, as mãos de morte, estarrecido, o negro Zé Alma Grande parou ao ouvir o sortilégio. Zé de Ogun deu um salto e um berro, atirou longe os sapatos, rodopiou na sala, virou 
orixá, no santo sua força duplicava. Ogunhê! gritou, e todos os presentes responderam: Ogunhê, meu pai Ogun!

-Ogunkapêdanmeji, danpelúoniban !

- repetiu Pedro Archanjo:- Ogun chamou as duas cobras e elas se ergueram para os soldados!

Ergueram-se os braços do orixá, as mãos de tenazes eram duas cobras: Zé Alma Grande, Ogun em fúria, partiu para Pedrito [...]. (p.195-196).

Pedro Archanjo sabe que o mito, mesmo se adormecido no coração do homem, mesmo se esquecido na alma, é capaz de despertar ante sua evocação. Desta forma, o antigo Zé de Ogun, que abandonara os terreiros para tornar-se criminoso, que repudiava as tradições do povo de santo, em plena batalha, vindo para destruir, ele termina por ser convocado ao serviço das divindades, voltando a assumir sua antiga identidade, e assim evita a destruição do terreiro e põe em fuga o comissário arbitrário, que será demitido da polícia, diante dos novos tempos que surgem no cenário social da Bahia que Jorge Amado descreve.

Por isso, pode-se afirmar que Pedro Archanjo é uma das mais instigantes e singulares personagens amadianas, talvez por se constituir, de fato, numa espécie de alter ego do 
próprio escritor, numa projeção das idealizações do papel do escritor, enquanto intelectual, e do próprio homem. Na verdade, Pedro Archanjo é uma figura aparentemente paradoxal: irresistível sedutor, conquistador de mulheres, exatamente para provar o senso moral dos "negros, pardos e mestiços"dos quais as teorias raciais alegavam a degenerescência,- no entanto, colocará a honra acima do amor e se negará a trair seu amigo-irmão Lídio Corró, deixando de amar a mulher dos seus sonhos, o seu verdadeiro amor, a "mais bela das belas, Rosa de Oxalá".

É que Pedro Archanjo, o invejável macho criado por Amado, é, na verdade, um homem sensível, que não apenas gosta, mas também ama a mulher, diferente do mito do Don Juan e seu fastio pela vida e desprezo pela mulher. Longe do conquistador compulsivo que se compraz no ato da conquista, na posse da "presa", Pedro Archanjo é cobiçado, desejado, pelo seu jeito especial de ser, distanciando-se da figura tradicional do "macho predador". As mulheres o amam em completa liberdade. Poder-se-ia dizer que o desejo feminino vai ao encontro do desejo do homem que é Pedro Archanjo. Por ele suspiram mocinhas e mulheres maduras, inexperientes donzelas e feridas mulheres da vida para quem ele, com delicadeza e firmeza, irá oferecer-lhes, não importa a idade, ou o momento, o prazer de amar regado com delicadeza e erotismo, aliviando os sofrimentos do corpo e da alma.

[...] Pedro Archanjo, um retado na cama, e quanta delicadeza! [...] (p.30) 
[...] Ela adormecera a sorrir, no calor das doces palavras de ternura, tão boas de ouvir e tão desejadas. [...] Rosália praticou em Alagoinhas, [...] e Pedro Archanjo a encontrou no Terreiro de Jesus comprando laranjas. Só então Rosália soube com certeza que era um ser humano e não uma coisa, um trapo, uma puta tãosomente [...]. (p.153).

Lutando em favor do seu povo, como um guerreiro, e ao mesmo tempo como um intelectual 'orgânico', Pedro Archanjo profetizará as transformações sociais que a sociedade brasileira conhecerá, numa clara demonstração do poder visionário de seu criador, Jorge Amado, ao fazer seu herói narrativo afirmar que:

[...] Eu penso que os orixás são um bem do povo. A luta da capoeira, o sambade-roda, os afoxés, os atabaques, os berimbaus, são bens do povo. [...] Sou a mistura de raças e homens, sou um mulato, um brasileiro. [...] Amanhã [...] tudo já terá se misturado por completo e o que hoje é mistério e luta de gente pobre, roda de negros e mestiços, música proibida, dança ilegal, candomblé, 
samba, capoeira, tudo isso será festa do povo brasileiro, música, balé, nossa cor, nosso riso, compreende? (p.201).

\section{Considerações Finais}

A releitura de Tenda dos milagres torna-se mais eficaz quando podemos constatar que a ideia de um progressivo branqueamento da população brasileira, tão cara aos adeptos e difusores das antigas teorias raciais, ainda impregnada nas mentes e corações de gerações inteiras, esta ideia é cada vez mais desmentida pela realidade. De fato, basta ver a cidade de Salvador, capital do Estado da Bahia, ou as cidades do Recôncavo baiano, para constatar que, de maneira irreversível, a sociedade baiana é, em sua maioria, negro-mestiça ${ }^{12}$.

De fato, o que se pode ver na Bahia, sobretudo na zona litorânea, historicamente povoada pelos antigos escravos negros, é a consolidação de uma mestiçagem de raças e culturas, com uma surpreendente riqueza dos patrimônios africanos, europeus e ameríndios, mesmo se, de modo explícito, a depender do espaço social, da situação, e do interlocutor, a coexistência democrática, a inclusão social deva ainda constituir-se em objeto de negociação que pode ir da simples concorrência à luta, por vezes acirrada, pelo reconhecimento dos direitos, logo, indo do diálogo à confrontação.

12 Os dados compilados pelo IBGE indicam que mais de 85\% da população de Salvador se diz negra ou parda, logo mestiça. 
Esse povo negro e mestiço, mergulhado na maior pobreza, sem a assistência dos poderes públicos de modo brutal até o início dos anos noventa do século XX e, que, de modo lento, começa a ser integrado graças às políticas de ação afirmativa a partir de 2003, é um enorme contingente populacional que jamais teve acesso ao emprego regular, sendo-lhe reservado apenas as atividades braçais dada sua baixa escolaridade.

Enfim, a própria indústria cultural, tal como prevista por Amado em Tenda dos Milagres, aciona, promove, difunde, veicula e alimenta toda uma ideia de mestiçagem cultural e enfatiza o caráter mestiço do povo baiano. O Pelourinho, cenário magnífico onde se desenrola Tenda dos Milagres, serve como principal atração turística da Bahia e é, no plano real, majoritariamente povoado por uma população negra e mestiça.

Por isso, pode-se dizer que, de modo inaugural, Amado antevê o que viria a ser uma consolidação da mestiçagem da sociedade baiana e brasileira, por extensão. E, para ilustrar a riqueza de um patrimônio cultural e humano que o escritor entende ser uma contribuição valiosa para a humanidade, apontando para a possibilidade de uma convivência pacífica entre os povos de diferentes etnias ou raças, é que Amado esboça a figura de Pedro Archanjo-Ojuobá, visto por dois mundos diferentes, pertencendo a mundos considerados em oposição, transitando entre culturas e construindo uma nova cultura que não exclui as demais, mas as ultrapassa, seleciona o que cada uma tem de melhor, elimina intransigências e assim supera dicotomias, afasta os perigos de um essencialismo identitário. 
Longe das armadilhas das identidades fixas, Amado nos mostra que a diversidade não exclui a unicidade, que sob a aparente diferença encontra-se a mesma humanidade que é sentida, percebida e vivida além de toda fronteira de raça, classe, cor, religião, língua... em sua permanente multiplicidade do Um. Assim é que posso ler esta personagem carregada de generosidade e amorosidade, uma personagem que nos sinaliza para um modo de ser onde prevalece o cuidado. Por isso, posso considerar que esta personagem está no que se convenciona chamar de entre-lugar, ou entre dois, em sua celebração do Diverso.

Enfim, onde tudo era dividido, só Pedro Archanjo filho de um pai que não o conheceu e de uma mãe que o deixaria órfão ainda criança - esta personagem que se entregava nos terreiros às divindades, que lia tratados, que debatia com os intelectuais da tradição branco-europeia, que nascendo em 1868 já não mais conheceria a escravidão, vivendo num tempo onde tudo parecia excludente, bipolar, só Pedro Archanjo-Ojuobá foi inteiro :

Não se dividiu em dois, com hora marcada para um e para outro, o sábio e o homem. Recusou subir a pequena escada do sucesso e alcançar um degrau acima do chão onde nasceu, chão das ladeiras, das tendas, das oficinas, dos terreiros, do povo. Não quis subir, quis andar para a frente e andou. Foi mestre Archanjo Ojuobá, um só e inteiro .(sic) (p.141). 
Como só pode ser um homem com a consciência de si e do mundo, que traz em si mesmo o Sim e o Não, que transita entre mundos e está no entre-lugar, espaço dos que reelaboram as tradições e as atualizam em contínuas traduções.

\section{Referências}

AMADO, Jorge. Tenda dos milagres. São Paulo: Martins Fontes, 1969

AMADO, Jorge. La boutique aux miracles. Traduzido por Alice Raillard. Paris: Stock, 1976.

BASBAUM, Leôncio. História sincera da República: das origens a 1889. 4. ed. São Paulo: Alfa-Ômega, 1976.

BAUMAN, Zygmunt. Vida líquida. Tradução Carlos Alberto Medeiros. Rio de Janeiro: Zahar, 2007.

BERNABE, Jean, «De l'oralité à la littérature antillaise » in (dir.) TETU LABSADE, Françoise. Littérature et dialogue interculturel. Sainte-Foy : Presses de l' Université Laval, 1997. BERND, Zilá. Literatura e identidade nacional. 2.ed. Porto Alegre: UFRGS, 2003.

CAMUS, Albert. Bahia de Tous les Saints article d'Albert Camus (Alger Républicain, 9 avril 1939) http://authologies. free.fr/amado.htm . 
FANON, Frantz. Pele negra, máscaras brancas. Rio de Janeiro: Fator, 1983.

FANON, Frantz. «Racisme et culture», Présence Africaine, Comte Rendu du $1^{\text {er }}$ Congrès International des écrivains et artistes noirs. Paris: Sorbonne, octobre, 1956.

FANON, Frantz. Os condenados da Terra. Rio de Janeiro: Civilização Brasileira, 1979.

FREYRE, Gilberto. Casa Grande \& Senzala. 25. ed, Rio de Janeiro: 1987.

GLISSANT, Edouard. Le Discours antillais. Paris: Seuil, 1981.

GOBINEAU, Arthur de, GOBINEAU, Joseph-Arthur. L'inégalité des races humaines, in http://www.philo5. com/Les\%20philosophes\%20Textes/Gobineau_InegaliteDesRacesHumaines.htm

LÉVI-STRAUSS, Claude, Race et Histoire, Race et culture. Paris : Albin Michel, UNESCO, 2001.

LIMA DE OLIVEIRA, Humberto Luiz. La perception de l' “Autre" à travers Ashini (1960) d' Yves Thériaul au Canada, Tenda dos milagres (La Boutique aux miracles, 1969), de Jorge Amado au Brésil et L' espérance macadam (1995), 
de Gisèle Pineau, aux Antilles.Thèse de doctorat. Sous la direction d' Alain Vuillemin. Université d' Artois, France, 2009.

LOPES, Helena Teodoro; SIQUEIRA, José Jorge; NASCIMENTO, Maria Beatriz. Negro e cultura no Brasil. Rio de Janeiro: Ibrade-Unesco, 1987.

NINA RODRIGUES, Raimundo. Os africanos no Brasil. 7.ed. Brasília: UNB, 1988.

ORTIZ, Renato. Cultura brasileira e identidade nacional. 4. ed. São Paulo: Brasiliense, 1994.

QUEIROZ FILHO, Teófilo de. Preconceito de cor e a mulata na literatura brasileira. São Paulo: Ática, 1975 RAILLARD, Alice. Conversando com Jorge Amado. Rio de Janeiro: Record, 1999.

SANSONE, Lívio. A internacionalização da cultura negra. Novos Estudos CEBRAP, n. 56, p.111- 136, mar. 2000, São Paulo.

SCHWARCZ, Lília Moritz, O espetáculo das raças: cientistas, instituições e questão racial no Brasil. 1870-1930. São Paulo : Companhia das Letras, 1995. 